\title{
AN INTEGRATED MODEL TO SELECT AN ERP SYSTEM FOR CHINESE SMALL- AND MEDIUM-SIZED ENTERPRISE UNDER UNCERTAINTY
}

\author{
Yu-Rong ZENG ${ }^{\mathrm{a}, \mathrm{b}}$, Lin WANG ${ }^{\mathrm{a}}$, Xian-Hao XU ${ }^{\mathrm{a}}$ \\ ${ }^{a}$ School of Management, Huazhong University of Science and Technology, Wuhan, 430074, China \\ ${ }^{b}$ School of Information Engineering, Hubei University of Economics, Wuhan, 430205, China
}

Received 26 February 2012; accepted 30 November 2013

\begin{abstract}
Enterprise Resource Planning (ERP) system is a vital investment that can significantly affect future competitiveness and performance of small- and medium-sized enterprises (SMEs). Selecting the best desirable ERP software covering both qualitative and quantitative factors has been the most critical problem for a long time. On the other hand, multiple criteria decision making has been found to be a useful approach to analyze conflicting factors. Qualitative criteria are often accompanied by ambiguities and vagueness. This makes fuzzy and grey logic become more natural approaches to handle this kind of problem. This paper presents a new approach for the selection of SME-specific ERP systems. Firstly, criteria for SMEs in China to evaluate the most suitable ERP system are put forward using group-discussing and anonymous questionnaire methods. An effective and practical algorithm, which is integrated of modified Delphi, analytic hierarchy process, fuzzy comprehensive evaluation and grey relational analysis, is utilized to convert the qualitative description to quantitative data to select the most appropriate alternative in the presence of vagueness and uncertainty. Finally, the potential use of the proposed model is illustrated through a case study.
\end{abstract}

Keywords: enterprise resource planning, SME, software selection, mulit-criteria decision making, fuzzy logic, grey theory.

JEL Classification: L86, L66.

\section{Introduction}

Severe market competition has changed the business environment dramatically. As a result, companies must reduce total costs, maximize return on investment, shorten lead times, and increase responsiveness to customer demands (Wang et al. 2015). Highly dynamic markets must implement effective enterprise information systems (ISs) to enhance competitive advantage (Wei et al. 2005). Enterprise resource planning (ERP) is an integrated and extensive consulate enterprise IS that combines all necessary business functions, such as production,

Corresponding author Lin Wang

E-mail: wanglin982@gmail.com 
planning, purchase, inventory control, sales, finance, and human resource management (Yazgan et al. 2009). A successfully implemented ERP can provide the following major benefits to organizations: (1) an automated business process; (2) timely access to management information; and (3) improved supply chain management through e-commerce (Liao et al. 2007; Umble et al. 2003).

The ERP software market continues to be one of the fastest-growing sectors in the information technology (IT) industry. In recent years, globalization and a competitive business environment have driven companies to invest considerable resources in the implementation of ERP systems (Ahmad, Cuenca 2013). Organizations deploy such systems to realize many intangible and tangible benefits and for strategic reasons. Although implementing an ERP system may be time consuming and costly, its benefits are worthwhile. Initially, ERP systems were mainly implemented in large companies; however, small- and medium-sized enterprises (SMEs) are crucial to many economies. Thus, suppliers have recently begun to offer SME-specific ERPs, and the adoption of this initiative in such enterprises has been catching up with that in large companies. SMEs differ significantly from large organizations; hence, an increasing number of such enterprises implement ERPs.

According to researchers, ERP is complicated by factors such as organizational change and process reengineering, high resource commitment, enterprise-wide implications, and the high potential business benefits and risks associated with such systems (Tchokogue et al. 2005). Thus, numerous companies have either abandoned their ERP projects before completion or have failed to achieve their business objectives after implementation; in fact, the failure rate of ERP implementation is high (Poba-Nzaou, Raymond 2012; Argyropoulou et al. 2008; Cebeci 2009). A successful ERP project involves managing the changes in business processes, selecting an ERP software system, implementing the chosen system, and assessing the practicality of the system. However, selecting an inappropriate ERP system results in either project failure or system weakening that deteriorates company performance (Hicks, Stecke 1995).

SMEs encounter more challenges by implementing ERP systems than large enterprises do given that a major disadvantage of SMEs is the lack of human and financial resources. Staff shortages in such enterprises may even cause production to stop to facilitate training (Snider et al. 2009). In addition, skills may need to be upgraded; however, SMEs typically cannot afford the necessary and extensive training. In fact, these enterprises rarely employ dedicated IT staff. Furthermore, SMEs may face challenges related to paying for major consulting support. Given the considerable financial investment and the potential risks and benefits, selecting a suitable ERP system according to the particular demand of SMEs is vital because this decision shapes organizational business (Karsak, Özogulb 2009; Tambovcevs 2012). The following other reasons that influence the selection of ERP systems in China also piqued our interest:

1) the high number of SMEs compared to that of large enterprises in China;

2) the many small ERP vendors in China that focus on SMEs;

3) the absence of a clear and suitable approach to selecting an ERP system for SMEs in China (Ge, Voss 2009). 
ERP system selection is tedious because of the complexity of business environments and the diversity of ERP alternatives. The process for determining the most appropriate ERP software from among a set of possible alternatives is a multi-criteria decision-making (MCDM) problem. Some scholars proposed simple evaluation models for this problem, and the scoring method is among the most popular approaches (Ptak 2000). The simple additive weighted value (AWV) method was also adopted; in this method, direct subjective weights are assigned to sub-criteria that reflect their relative contributions to the criteria of a preceding weight (Argyropoulou et al. 2008). Wei and Wang (2004) designed an analysis hierarchy process (AHP)-based approach to ERP system selection, and a similar approach was adopted by Karaarslan and Gundogar (2009).

Complicated approaches were also used extensively by many experts. Teltumbde (2000) suggested 10 criteria for evaluating ERP projects and constructed a framework based on the nominal group technique and AHP for decision-making. Lee and Kim (2001) combined the analytic network process with a zero-one goal programming model to select an IS. Ayağ and Özdemir (2007) selected an ERP system via the fuzzy extension of an analytic network process. Karsak and Özogulb (2009) developed a decision framework for ERP software selection based on quality function deployment, fuzzy linear regression, and zero-one goal programming. Cebeci (2009) proposed a fuzzy AHP-based method that utilized a balanced scorecard for selecting ERP systems in the textile industry. Yazgan et al. (2009) developed the complicated artificial neural network-based approach with the analytic network process approach.

These studies have contributed substantially to this research area by advocating the importance of ERP system selection methods. Moreover, these works have generated additional insight by establishing a comprehensive framework to identify the customized evaluation criteria that can direct SMEs. However, these indices cannot be utilized directly by Chinese SMEs. Certain simple, AWV methods neither produce reasonable weights nor ensure resource feasibility (Wei, Wang 2004). Other mathematical programming methods are complicated for SMEs and cannot store the sufficient detailed attributes that are difficult to quantify. Thus, attributes for consideration are restricted to a few financial factors, such as costs and benefits. Furthermore, many approaches consider only the interests of internal managers and do not conceptualize a comprehensive process to combine the evaluation mechanisms of different data sources for the objective selection of an ERP system. In fact, selecting the most suitable ERP system is difficult for most companies, and limited information is available to address this evaluation problem. Fuzzy comprehensive evaluation (FCE) and grey theory must be applied to this comprehensive evaluation problem because such analysis is highly subjective and is related to inexact and grey information (Han, Liu 2011). A novel model that integrates qualitative and quantitative analyses based on fuzzy and grey logic can enhance MCDM analysis approaches.

The main aim of the present work is to establish a systematic and comprehensive evaluation model for the selection of a SME-oriented ERP system. The remainder of this paper is organized as follows. An ERP system selection procedure is proposed; then, the evaluation criteria are presented and an integrated assessment model is designed. Subsequently, a case application is discussed to illustrate the proposed method. Finally, the conclusions drawn from this study and future research directions are presented. 


\section{ERP system selection procedure}

Step 1. A project team is formed for business process re-engineering (BPR) purposes. This team consists of decision makers, the senior representatives of user departments, and functional experts. BPR is very useful for rationalizing and standardizing the workflows of all business processes, and companies are always advised to reengineer their business processes to take advantage of the "best practices" for ERP systems (Newman, Zhao 2008). A project team should also describe the company goals in detail. With the implementation of BPR, these objectives can appropriately be incorporated into the decision model; ERP systems that cannot meet the application requirement and effectively support the achievement of SMEs' strategic goals should not be considered. This step helps SMEs determine a clear project scope and simplify the selection process. If a company lacks sufficient experiences in BPR, external assistance may be obtained from consulting companies, including teams from universities.

Step 2. All possible information about ERP vendors is collected, and unqualified vendors are filtered out. The characteristics that reflect system requirements are transferred to either a questionnaire or a checklist of the system specifications. Much information about ERP vendors and systems should be derived from professional magazines, yearbooks, exhibitions, the Internet, and other sources; the listed vendors are invited to provide information through responses to designated questions as well. Clearly unqualified vendors are then eliminated to reduce the number of candidates.

Step 3. The evaluation criteria are established and weights are assigned to each criterion. Companies usually consider the following aspects when selecting an ERP project: (1) the capability of a system to support the business process; (2) the plan of a system with respect to executing the business strategy and meeting goals; (3) the technical requirements; (4) the ability of vendors to support system implementation, maintenance, and upgrades; and (5) the dynamic methodologies of business processes and project management. That is, the criteria originate from the problem described above.

Step 4. Potential vendors are interviewed and detailed information is collected.

Step 5. The data are obtained from the external professional reports and from firsthand materials to evaluate the ERP suitability from different aspects.

Step 6. The comprehensive evaluation result is computed to determine the final ERP suitability.

Step 7. The most appropriate ERP system is selected.

\section{Factors affecting ERP system selection and criteria for SMEs}

\subsection{Factors affecting selection}

Commercial ERP packages cannot provide a once-and-for all business model for all processes in all industries. Thus, no single ERP software package can meet all firm functionalities or all special business requirements (Yang et al. 2007). Moreover, SMEs rarely employ 
dedicated IT staff, let alone establish a formal IT department. Thus, major projects face higher external and internal risks than large organizations do. Externally, SMEs are more fragile than large companies are and encounter more difficulty in obtaining credit (Snider et al. 2009). Such external risks can lead to project delays or even abandonment. Internally, SMEs may find re-engineering projects difficult to implement because of limited spare resources. Overall, such enterprises may face significant challenges in terms of adopting technology. Finally, the cost of ERP implementation may be proportionally higher for SMEs than for large organizations; thus, the former may be more severely affected by failure. An SME must therefore choose a flexible ERP system and a co-operative vendor that effectively responds to customer requirements.

To understand and evaluate the acquisition and selection process, many studies identified the factors that affect ERP selection in SMEs and provided criteria to optimize the selection process (Haddara, Zach 2011). The results show that internal organizational factors, such as business complexity and change management, and external factors, including supply chain partners and the pressure of value networks, affect the ERP selection process in Greek SMEs (Argyropoulou et al. 2008). Other studies conducted with Australian SMEs suggest that acquisition decisions are significantly influenced by cost drivers, functional requirements, flexibility, and scalability of the ERP system (Reuther, Chattopadhyay 2004), and the degree of ERP fit with business processes (Marsh 2000). Moreover, the results of a comparison of small, medium-sized, and large Finnish enterprises indicate that small companies consider the ample information for decision making and the sufficient participation of different organizational functions in the ERP system selection phase to be problematic (Laukkanen et al. 2007).

\subsection{Section factors for SMEs and scoring principles}

\subsubsection{Factor selection for SMEs}

Selecting a suitable ERP project involves various approaches and corresponding factors. Some papers discussed this problem from different aspects; for instance, Teltumbde (2000) considered factors such as strategy fit, technology, risk, implementation capability, flexibility, cost, benefit, business functionality, technology, and vendor credentials. The criteria used by Wei and Wang (2004) are as follows: total cost, implementation time, benefits, risks, strategic fitness, function and technology, vendor's ability, and vendor's reputation. Onut and Efendigi (2010) proposed the following criteria: quality, costs (purchasing and consulting costs), and reputation (vendor's ability and condition). Yazgan et al. (2009) applied financial analyses, general characteristics, system control and software design, production planning, and data and knowledge properties as criteria.

On the cornerstones of these works, some scholars proposed special factors to select ERP systems according to the characteristics of SMEs. Everdingen et al. (2000) stated that the fit of ERP with organizational business processes is the most important selection factor for Nordic European SMEs. Another scholar developed criteria that can aid SMEs in the selection process, including local support, affordability, and suppliers' business domain knowledge (Rao 2000). Deep et al. (2008) proposed a methodology for choosing the best-fit 
ERP system with made-to-order SMEs environments. Argyropoulou et al. (2008) considered the following factors in selecting ERP vendors for SMEs: strategic issues, functionality, ease of customization, usefulness, ease of implantation, cost, time, system issues, feel-good factor, and vendor's features.

\subsubsection{Proposed factors for SMEs}

The present study uses the modified Delphi technique to confirm the criteria for ERP system evaluation. This method integrates the judgments of a number of experts who cannot assemble physically and facilitates feedback, debate, and commenting. This technique primarily aims to achieve consensus among a diverse group of participants (Czinkota, Ronkainen 2005). To conduct a successful study, appropriate experts must participate. The criteria for expert selection are as follows: an active career in a related business for at least 10 years with rich experiences in information management and ERP implementation; a global vision beyond local and temporary concerns; as well as accessibility and willingness to engage in intellectual dialogue.

The necessary information is gathered by adopting the group discussion and anonymous questionnaire methods simultaneously. The authors choose 15 experts and analyze their proposed ideas. According to the principle of rationality, comparability, and maneuverability, the following factors are selected as the criteria for the comprehensive ERP system evaluation.

(1) Vendor factors (VF)

$\mathrm{P}_{1}$ : Vendor's reputation. This factor can be assessed based on a vendor's financial condition and credentials. Sometimes, this factor can be evaluated according to the widely accepted and authoritative rank of a third-party institution.

$\mathrm{P}_{2}$ : Experience in the SME industry. This key factor is crucial to the success of ERP system implantation in such enterprises.

$\mathrm{P}_{3}$ : Terms and period of guarantee. A supplier is also responsible for the ongoing support, maintenance, upgrading, and integration of a system. The services of a vendor generally include responding to technical queries, reporting and resolving faults, fixing bugs in the software, assisting in system design, conducting online tutorials, and providing online documentation and product trials. SMEs always expect a long and free guarantee period.

$\mathrm{P}_{4}$ : Research and development $(\mathrm{R} \& \mathrm{D})$ ability. The business of SMEs always changes relatively and rapidly; hence, upgrades are inevitable. If an ERP vendor possesses poor R\&D ability, an ideal ERP system with improved functions may be unaffordable.

(2) Investment factors (IF)

$\mathrm{P}_{5}$ : Initial cost. This price includes licensing arrangement and product and technology costs.

$\mathrm{P}_{6}$ : Maintenance and upgrading cost. This cost involves adapting and integration, training, supporting, and maintenance and upgrading costs.

$\mathrm{P}_{7}$ : Implementation time. SMEs usually expect an implementation schedule to not exceed two years. 


\section{(3) Quality factors (QF)}

The quality criteria are mainly derived from the IEEE standard for software quality metrics methodology (IEEE Std. 1061-1992); this standard is widely used by researchers and practitioners to evaluate software quality (IEEE Standards Board 1992). The IEEE standard defines software quality characteristics as being composed of six external attributes, namely, functionality, reliability, efficiency, usability, maintainability, and portability. In the first phase, expert advice regarding the most related quality criteria associated with SMEs is collected and analyzed; then, the different ideas are collated and a report is sent to the experts. Subsequently, the experts modify their selections; in the second round of analysis, four important external attributes are confirmed and discussed among five experts.

$\mathrm{P}_{8}$ : Functionality (suitability, accuracy, interoperability, and compliance). All the modules are evaluated, including general system specifications and the modules of production, material management, financial management, quality management; sales and distribution, maintenance management, and human resources.

$\mathrm{P}_{9}$ : Reliability (maturity, fault tolerance, and recoverability).

$\mathrm{P}_{10}$ : Maintainability (analyzability, changeability, stability, and testability).

$\mathrm{P}_{11}$ : Usability (understandability, learnability, and operability).

\section{(4) BPR-related factors $(B F)$}

$\mathrm{P}_{12}$ : Good fit with the company's business process. The most significant enterprise system implementation failures occur when a new technology's capabilities and needs are mismatched with the organization's existing business processes and procedures (Argyropoulou et al. 2008; Marsh 2000). This factor is critical for SMEs.

$\mathrm{P}_{13}$ : Ease of customization. This factor can be evaluated based on the level of customization required, the necessary time for customization, the development tool used, robustness, and the proven reliability of similar customizations.

$\mathrm{P}_{14}$ : Ease of implementation. This factor can be evaluated according to the ease of administration, the level of technical support required, the usefulness of user documentations, and the capability to handle transactions.

$\mathrm{P}_{15}$ : Capability of systems to meet strategic aims. Primary strategic aims include the operations flow standardization, business process optimization, construction of customer-centric policies, and operations management support.

\subsubsection{Data collecting and scoring principles}

Data sources can be classified in two ways: (a) for quantitative factors $\mathrm{P}_{5}$ to $\mathrm{P}_{7}$, data originate from the bidding files of vendors; (b) portions of data are derived from the objective and the subjective data obtained through external professional reports and through internal interviews with vendors, respectively. Professional organizations, such as consulting companies or research institutes, employ many experts to analyze ERP information, including market share, vendor size, system performance, and others. The professional studies conducted by these experts help decision makers obtain an overview of ERP systems and vendors. Furthermore, decision makers can extract important attributes from these reports. 
Although a certain criterion may be evaluated quantitatively, its direct effect on ERP system selection is difficult to assess. To this end, a score (1 to 10) is assigned according to the practical condition for each criterion. For qualitative factors $\mathrm{P}_{3}, \mathrm{P}_{4}$, and $\mathrm{P}_{8}$ to $\mathrm{P}_{15}$, the scores are given by specialists who can be selected from among the experts mentioned in Section 2.2.2. Scoring is based on specialist experience as per the external professional reports and the subjective data obtained from internal interviews with vendors.

The scoring rules for the other factors are presented as follows; for instance, those for $\mathrm{P}_{1}$ are shown in Table 1.

To assess the effect of experience in the SME industry on an ERP system, we reference successful applications in the SME industry. The scoring rules for $\mathrm{P}_{2}$ are listed in Table 2.

For quantitative cost factors, the detailed scoring rules for $\mathrm{P}_{5}$ and $\mathrm{P}_{6}$ are presented in Table 3. An excessively high price is obviously unacceptable, and an excessively low price is also discouraged due to unreliable quality and delivery. Although one factor may be quantitative, judging its direct effect on ERP system selection remains difficult for experts. Thus, the scopes developed for scoring enable experts to generate independent judgments within an accepted scope. A similar approach is adopted for $\mathrm{P}_{7}$.

An implementation that exceeds the set time schedule inevitably disrupts production. With respect to implementation time factors, the detailed scoring rule for $\mathrm{P}_{7}$ is indicated in Table 4. In this study, implementation time and schedule time data are provided by an ERP vendor. The data from the previous ERP implementation case are used for evaluation.

Table 1. Scoring rules for $\mathrm{P}_{1}$

\begin{tabular}{cccccc}
\hline Specificity & Rank 1-2 & Rank 3-4 & Rank 5-7 & Rank 8-10 & others \\
\hline Score scope & $10-9$ & $8-7$ & $6-4$ & $3-1$ & 0 \\
\hline
\end{tabular}

Table 2. Scoring rules for $\mathrm{P}_{2}$

\begin{tabular}{cccccc}
\hline $\begin{array}{c}\text { Quantity of successful } \\
\text { applications in SMEs industry }\end{array}$ & $>8$ & $5-7$ & $2-4$ & 1 & 0 \\
\hline Score scope & $9-10$ & $7-8$ & $4-6$ & $1-3$ & 0 \\
\hline
\end{tabular}

Table 3. Scoring rules for $\mathrm{P}_{5}$ and $\mathrm{P}_{6}$

\begin{tabular}{cccccc}
\hline $\begin{array}{c}\text { Higher than average price } \\
\text { of all tenders (\%) }\end{array}$ & $(-30,-15]$ & $(-15,0]$ & $(0,15]$ & $(15,30]$ & others \\
\hline Score scope & $10-9$ & $8-7$ & $6-5$ & $4-3$ & 0 \\
\hline
\end{tabular}

Table 4. Scoring rules for $\mathrm{P}_{7}$

\begin{tabular}{ccccc}
\hline $\begin{array}{c}\text { Implementation } \\
\text { time }\end{array}$ & $\begin{array}{c}\text { adherence to } \\
\text { time schedule }\end{array}$ & $\begin{array}{c}\text { later than } \\
\text { schedule 6 months }\end{array}$ & $\begin{array}{c}\text { later than schedule } \\
12 \text { months }\end{array}$ & $\begin{array}{c}\text { later than schedule } \\
24 \text { months }\end{array}$ \\
\hline Score scope & 10 & $9-7$ & $6-4$ & $3-0$ \\
\hline
\end{tabular}




\section{Proposed integrated model for ERP evaluation}

\subsection{Rationales behind the application of FCE and grey theory}

The FCE is based on fuzzy transform theory and the principle of maximal membership degree. This evaluation is widely adopted in a variety of fields (Wang, Zeng 2005; Kumar et al. 2011; Zeng et al. 2012). Nonetheless, the grey-based assessment approach is a viable option if information and experience are limited (Deng 2008; Hsu, Wen 2000); however, this approach cannot be used when evaluation rules are fuzzy. In fact, fuzziness is observed in the assessment of ERP vendors.

The varying preferences and abilities of evaluators inevitably produce certain grey evaluation information. If the fuzzy method alone is utilized when changes in the outer phenomena randomly conceal the nature of circumstances or when the interrelationship of factors is complex, then comprehensive and adequate information cannot be obtained (Kersuliene, Turskis 2011; Xu et al. 2011; Wang et al. 2013a, 2013b; Xu et al. 2015). Moreover, we cannot maximize the advantage of fuzziness in the evaluation rules if grey theory alone is applied. Therefore, this study combines grey theory with fuzzy evaluation to construct a fuzzy matrix of membership degree and compute the overall suitability evaluation of ERP vendors via a fuzzy algorithm.

Considering the special characteristics of SMEs, an integrated and reliable model of the meta-synthesis of qualitative and quantitative data is utilized to evaluate the suitability of an ERP system under a highly uncertain environment with limited data and information. This model considers the incomplete information (greyness) in expert judgment, facilitates the fuzzy and comprehensive evaluation of the comprehensive grey analysis procedure in the process of evaluation and ranking, and generates a favorable approach for quantitative analysis. This approach is more reliable and scientific than either the fuzzy evaluation method or the grey evaluation method alone.

\subsection{Steps of the proposed meta-synthesis method}

A systematic algorithm that integrates AHP, fuzzy comprehensive evaluation, and grey relational analysis is utilized to convert qualitative descriptions into quantitative data. Then, objective and subjective evaluations are combined to determine final ERP suitability. The basic concept can be presented as follows: a sample matrix can be obtained when experts score in consideration of the greyness of expert judgment. Grey statistics can be determined using several whitening functions; moreover, the comprehensive fuzzy and grey evaluation approach is used to evaluate and rank all expert preferences and determine the group preference. The detailed steps of this process are as follows.

Step 1. The weight of each criterion is confirmed. The weight of each criterion can be confirmed through many methods, such as entropy value, Delphi, and the AHP method. AHP permits inconsistencies because people are more likely to be cardinally inconsistent than cardinally consistent in judgment. Moreover, AHP also applies the principle of hierarchic composition to derive the composite priorities of alternatives with respect to the multiple criteria derived from the individual priorities of each criterion. In fact, AHP is an effective 
multi-criteria decision making tool to determine the relative priorities to be assigned to different criteria and the alternatives that characterize a decision (Yuen 2010). Thus, the weight of each criterion can be identified via AHP; that is, $W=\left\{w_{1}, w_{2}, \ldots, w_{n}\right\}$. Notably, $w_{i}$ is the corresponding weight of criterion $\mathrm{P}_{i}$.

Step 2. The sample matrix is confirmed. Supposing that the number of experts is $r, E=$ $\left\{E_{1}, E_{2}, \ldots, E_{r}\right\}$. Assuming that the value of criterion $i$ given by expert $k(k=1,2, \ldots, r)$ is $d_{k i}$, the sample matrix for all the experts can be expressed as follows:

$$
D=\left[\begin{array}{cccc}
d_{11} & d_{12} & \cdots & d_{1 n} \\
d_{21} & d_{22} & \cdots & d_{2 n} \\
\vdots & \vdots & \vdots & \vdots \\
d_{r 1} & d_{r 2} & \cdots & d_{r n}
\end{array}\right]
$$

Step 3. The evaluation class is confirmed. The evaluation class is set as $m$ according to scientific assessment theory. Thus, the comprehensive evaluate standard matrix is expressed as $V=\left\{v_{1}, v_{2}, \ldots, v_{m}\right\}$.

Step 4. The grey number of evaluation is confirmed. Grey categories should be confirmed through qualitative analysis. The corresponding whitening functions (WFs) that are used extensively are as follows:

1) The corresponding WF is determined as follows given upper level, grey number $\otimes$ $\in[0, \infty]:$

$$
f_{1}\left(d_{k i}\right)= \begin{cases}\frac{d_{k i}}{d_{1}}, & d_{k i} \in\left[0, d_{1}\right] \\ 1, & d_{k i} \in\left[d_{1}, \infty\right] . \\ 0, & d_{k i} \in(-\infty, 0)\end{cases}
$$

2) The corresponding WF is calculated as follows given middle level, grey number $\otimes$ $\in\left[0, d_{1}, 2 d_{1}\right]:$

$$
f_{2}\left(d_{k i}\right)= \begin{cases}\frac{d_{k i}}{d_{1}}, & d_{k i} \in\left[0, d_{1}\right] \\ 2-\frac{d_{k i}}{d_{1}}, & d_{k i} \in\left[d_{1}, 2 d_{1}\right] . \\ 0, & d_{k i} \notin\left(0,2 d_{1}\right]\end{cases}
$$

3) The corresponding WF is computed as follows given low level, grey number $\otimes \in$ $\left[0, d_{1}, d_{2}\right]:$

$$
f_{3}\left(d_{k i}\right)= \begin{cases}1, & d_{k i} \in\left[0, d_{1}\right] \\ \frac{d_{2}-d_{k i}}{d_{2}-d_{1}}, & d_{k i} \in\left[d_{1}, d_{2}\right] . \\ 0, & d_{k i} \notin\left(0, d_{2}\right]\end{cases}
$$


The turning points of the WFs are usually called thresholds. In this study, $d_{1}$ is a threshold for $f_{1}\left(d_{k i}\right)$ or $f_{2}\left(d_{k i}\right)$ while $d_{1}$ and $d_{2}$ are thresholds for $f_{3}\left(d_{k i}\right)$. The value of a threshold can be obtained in two ways: (1) the threshold is confirmed in accordance with guidelines or experience through the analog method. The threshold determined with this approach is known as the objective threshold. (2) The maximum, minimum, and equivalent values from the sample matrix can be considered the upper limit, lower limit, and the equivalent value, respectively. The threshold confirmed by this approach is labeled the relative threshold.

Step 5. Grey statistics are calculated. $f_{j}\left(d_{k i}\right)$ represents the degree of $d_{k i}$ that belongs to evaluation class $j(j=1,2, \ldots, m)$ and can be obtained with Equations 1 to 3 . Thus, $n_{i j}$, which indicates that the statistical grey number of criterion $i$ belongs to the valuation class $j$ of all the experts, can be calculated using Equation 4:

$$
n_{i j}=\sum_{k=1}^{r} f_{j}\left(d_{k i}\right) .
$$

The total statistical grey number of $i, n_{i}$, can be calculated with Equation 5 :

$$
n_{i}=\sum_{j=1}^{m} n_{i j} .
$$

Step 6. The grey evaluation value and the fuzzy matrix are calculated. The weight of criterion $i$ belongs to valuation class $j$ and is denoted by $r_{i j}$. This variable can be calculated with the formula $r_{i j}=n_{i j} / n_{i}$. Thus,

$$
R=\left[\begin{array}{cccc}
r 11 & r_{12} & \ldots & r_{1 m} \\
r 21 & r_{22} & \ldots & r_{2 m} \\
\vdots & \vdots & \vdots & \vdots \\
r_{n 1} & r_{n 2} & \ldots & r_{n m}
\end{array}\right]
$$

Step 7. The fuzzy comprehensive matrix is calculated:

$$
B=\left(b_{1}, b_{2}, \ldots, b_{m}\right)=\left(w_{1}, w_{2}, \ldots, w_{n}\right) \cdot\left[\begin{array}{cccc}
r 11 & r_{12} & \ldots & r_{1 m} \\
r 21 & r_{22} & \ldots & r_{2 m} \\
\vdots & \vdots & \vdots & \vdots \\
r_{n 1} & r_{n 2} & \ldots & r_{n m}
\end{array}\right] .
$$

Step 8. The result of comprehensive evaluation is calculated. The degree of evaluation can be obtained through $C=\left(v_{1}, v_{2}, \ldots, v_{m}\right)^{T}$. Consequently, $Z$ can be determined using the formula $Z=(W \cdot R) \cdot C$; this process evaluates the "suitability" of an ERP system. 


\section{Case application}

\subsection{Company background and ERP vendors}

\subsubsection{Studied company and problem}

The studied company (subsequently termed company DD for anonymity) is a mid-sized food handling enterprise located in JingZhou City, Hubei Province, China. The company was established in 2007 and employs roughly 280 staff members. The firm released over 50 types of products in 2011 and had an average annual turnover of approximately 15 million $\mathrm{RMB}$ in the past three years. This company mainly produces of different foods composed of freshwater fish. SMEs are defined in Wikipedia as enterprises with 25-500 employees; nonetheless, Chinese SMEs tend to be larger than those in the West. According to the "Industrial Classification of National Economy (GB/T4754-2011)" (National Bureau of Statistics of China 2011), enterprises with different turnovers or total numbers of staff members are classified as large-, medium-, small-, and micro-sized enterprises (see Table 5). Company DD reports a total turnover of lower than 400 million RMB and less than 1,000 staff members in total; therefore, this company is a typical SME.

Table 5. Size Classification of SMEs in China

\begin{tabular}{ccccccc}
\hline Type & Index & Unit & Large & Medium & Small & Micro \\
\hline \multirow{2}{*}{ Industry } & Personnel(X) & Person & $\mathrm{X} \geq 1000$ & $300 \leq \mathrm{X}<1000$ & $20 \leq \mathrm{X}<300$ & $\mathrm{X}<20$ \\
\cline { 2 - 7 } & Turnover(Y) & $10000 \mathrm{RMB}$ & $\mathrm{Y} \geq 40000$ & $2000 \leq \mathrm{Y}<40000$ & $300 \leq \mathrm{Y}<2000$ & $\mathrm{Y}<300$ \\
\hline
\end{tabular}

As a result of its rapid development, this company faced the following problems in lieu of an ERP system: (1) production was always postponed due to unsatisfactory supply management; (2) unqualified marketing management generated excess inventories of unpopular products; (3) branches in other cities were not monitored effectively; (4) administration was scattered due to a lack of assistance from effective information management. Owing to the need to enhance its competitive advantage, the top management of company DD decided to implement organizational changes. A BPR consulting program was initiated with the help of a team from a university with rich related experiences. Following the necessary consultation, company DD decided to select one ERP system from among $S_{1}, S_{2}$, and $S_{3}$.

\subsubsection{Three alternatives}

System $S_{1}$ is a visionary product that takes advantage of an open and multi-tier browserserver architecture. Ease of customization and maintainability were high in all business aspects, with the exception of material management. The provider was ranked fourth in terms of market share in China and reported a sales growth rate of over $30 \%$ over the past three years. The local representation of this provider in Hubei Province was strong; 
thus, the company could take full responsibility for the implementation, maintenance, and support of the system. The infrastructure provider was also a strong and reliable provider of hardware and network-related products and services. Nonetheless, the proposed cost exceeded the budget by $8 \%$.

System $\mathrm{S}_{2}$ provided a rational platform that can meet the majority of the company's needs. The vendor in China was a small software company with a limited experience in ERP installation projects, particularly in the SME industry. The offered product possessed a moderate local market share, and the company had developed an aggressive worldwide expansion plan. The product price was low; furthermore, the installation team appeared friendly and was willing to cooperate.

Unlike System $S_{1}$, the price of System $S_{3}$ was lower than the budget by $15 \%$. Furthermore, this system was a well-established international package with a number of successful implementations in China. However, the vendor had limited experience in the SME industry, although it was among the top $10 \mathrm{ERP}$ software vendors in China. The software was easily configured and strong in terms of production management, quality management, purchasing, and order processing. However, the product exhibited shortcomings with respect to the maintenance management and scheduling modules. The vendor's local representation was strong and can support company DD consistently.

\subsection{Results and analysis}

\subsubsection{Comparison of the proposed model with the AWV method for system $S_{1}$}

The steps discussed in Section 4.2 are detailed as follows:

Step 1. The weight of each criterion is confirmed. In this study, we applied AHP to confirm the weight of each criterion. A team of 10 experts out of the 15 mentioned in Section 3.2.2 was constructed to formulate the ERP project; 5 were experts in business management, and the other 5 were specialists in information management. Each expert was given specific responsibilities to confirm the weights of the criteria. A steering committee was also formed with the business heads. The criteria for the business representatives was similar to that used by Teltumbde (2000): the member should have served for at least five years in the company, have exposure to at least three business areas, have worked on at least one special project, and have exhibited visible conceptual skills. The IS representatives were selected according to the same criteria except that exposure to three business areas was replaced with exposure to three systems analysis and development processes. In this case study, five business representatives and one IS representative were employed by company DD; four IS representatives operated outside the market, including one professor from a university.

Pairwise comparisons were conducted with main criteria in relation to the goal, as displayed in Table 6; such comparisons of sub-criteria with the main criteria are shown in Tables 7 to 10 . 
Table 6. Pairwise comparisons of main criteria with respect to the goal.

\begin{tabular}{ccccc}
\hline $\begin{array}{c}\text { G } \\
\text { (ERP system selection) }\end{array}$ & VF & IF & QF & BF \\
\hline VF & 1 & $1 / 2$ & $1 / 2$ & $1 / 2$ \\
\hline IF & 2 & 1 & 2 & 1 \\
\hline QF & 2 & $1 / 2$ & 1 & $1 / 2$ \\
\hline BF & 2 & 1 & 2 & 1 \\
\hline$n=4 ; \lambda \max =4.0604 ; C I=0.0201 ; R I=0.90 ; C R=0.0224<0.1$. & &
\end{tabular}

Note: Consistency Index $(C I)$, Consistency Ration $(C R)$, and Random Consistency Index $(R I)$ values are obtained with the approach proposed by Saaty (1980).

The relative priorities are as follows: $w_{\mathrm{VF}}=0.1394, w_{\mathrm{CF}}=0.3317, w_{\mathrm{QF}}=0.1972, w_{\mathrm{IF}}=0.3317$.

Table 7. Pairwise comparisons of sub-criteria with respect to VF

\begin{tabular}{ccccc}
\hline $\mathrm{VF}$ & $\mathrm{P}_{1}$ & $\mathrm{P}_{2}$ & $\mathrm{P}_{3}$ & $\mathrm{P}_{4}$ \\
\hline $\mathrm{P}_{1}$ & 1 & $1 / 2$ & 1 & $1 / 2$ \\
\hline $\mathrm{P}_{2}$ & 2 & 1 & 3 & 2 \\
\hline $\mathrm{P}_{3}$ & 1 & $1 / 3$ & 1 & $1 / 2$ \\
\hline $\mathrm{P}_{4}$ & 2 & $1 / 2$ & 2 & 1 \\
\hline$n=4 ; \lambda \max =4.0457 ; C I=0.0152 ; R I=0.90 ;$ \\
$C R=0.0169<0.1$.
\end{tabular}

Note: The relative priorities are as follows: $w_{1}{ }^{*}=$ $0.1608, w_{2}^{*}=0.4233, w_{3}^{*}=0.1453, w_{4}^{*}=0.2705$.
Table 8. Pairwise comparisons of sub-criteria with respect to IF.

\begin{tabular}{cccc}
\hline IF & $\mathrm{P}_{5}$ & $\mathrm{P}_{6}$ & $\mathrm{P}_{7}$ \\
\hline $\mathrm{P}_{5}$ & 1 & 2 & 3 \\
\hline $\mathrm{P}_{6}$ & $1 / 2$ & 1 & 2 \\
\hline $\mathrm{P}_{7}$ & $1 / 3$ & $1 / 2$ & 1 \\
\hline$n=3 ; \lambda \max =3.0092 ; C I=0.0046 ; R I=$ \\
$0.58 ; C R=0.0079<0.1$.
\end{tabular}

Note: The relative priorities are as follows: $w_{5}^{*}=0.5396, w_{6}^{*}=0.2970, w_{7}^{*}=0.1634$.

Table 9. Pairwise comparisons of sub-criteria with respect to QF.

\begin{tabular}{ccccc}
\hline QF & $\mathrm{P}_{8}$ & $\mathrm{P}_{9}$ & $\mathrm{P}_{10}$ & $\mathrm{P}_{11}$ \\
\hline $\mathrm{P}_{8}$ & 1 & 1 & 3 & 3 \\
\hline $\mathrm{P}_{9}$ & 1 & 1 & 2 & 2 \\
\hline $\mathrm{P}_{10}$ & $1 / 3$ & $1 / 2$ & 1 & 1 \\
\hline $\mathrm{P}_{11}$ & $1 / 3$ & $1 / 2$ & 1 & 1 \\
\hline$n=4 ; \lambda \max =4.0206 ; C I=0.0069 ; R I=0.90 ; C R=0.0076<0.1$. & &
\end{tabular}

Note: The relative priorities are as follows: $w_{8}{ }^{*}=0.3915, w_{9}{ }^{*}=0.3197, w_{10}{ }^{*}=0.1444, w_{11}{ }^{*}=0.1444$.

Table 10. Pairwise comparisons of sub-criteria with respect to BF.

\begin{tabular}{ccccc}
\hline $\mathrm{BF}$ & $\mathrm{P}_{12}$ & $\mathrm{P}_{13}$ & $\mathrm{P}_{14}$ & $\mathrm{P}_{15}$ \\
\hline $\mathrm{P}_{12}$ & 1 & 2 & 1 & 1 \\
\hline $\mathrm{P}_{13}$ & $1 / 2$ & 1 & 1 & $1 / 2$ \\
\hline $\mathrm{P}_{14}$ & 1 & 1 & 1 & $1 / 2$ \\
\hline $\mathrm{P}_{15}$ & 1 & 2 & 2 & 1 \\
\hline
\end{tabular}

$n=4 ; \lambda \max =4.0604 ; C I=0.0201 ; R I=0.90 ; C R=0.0224<0.1$.

Note: The relative priorities are as follows: $w_{12}{ }^{*}=0.2865, w_{13}{ }^{*}=0.1703, w_{14}{ }^{*}=0.2026, w_{15}{ }^{*}=0.3407$. 
The global weights of all sub-criteria can be obtained as follows by applying the relative priorities of the main criteria and the sub-criteria:

$$
\begin{aligned}
W=\left(w_{1}, w_{2}, \ldots, w_{15}\right)^{\mathrm{T}}= & (0.0224,0.0590,0.0203,0.0377,0.1790,0.0985,0.0542,0.0772, \\
& 0.0630,0.0285,0.0285,0.0950,0.0565,0.0672,0.1130)^{\mathrm{T}} .
\end{aligned}
$$

Step 2. The sample matrix is confirmed by 10 experts. Sample matrix $D$ is expressed as follows for the comprehensive evaluation of an ERP system (A) via scores given by 10 experts:

$$
D=\left[\begin{array}{lllllllllllllll}
8 & 8 & 5 & 8 & 6 & 5 & 5 & 8 & 8 & 8 & 8 & 7 & 6 & 6 & 8 \\
8 & 8 & 6 & 7 & 6 & 6 & 6 & 7 & 7 & 8 & 8 & 6 & 7 & 7 & 8 \\
7 & 7 & 6 & 9 & 5 & 6 & 6 & 8 & 8 & 8 & 8 & 7 & 6 & 6 & 7 \\
7 & 8 & 5 & 7 & 5 & 6 & 5 & 8 & 7 & 8 & 9 & 6 & 7 & 7 & 8 \\
8 & 8 & 6 & 7 & 6 & 5 & 6 & 7 & 9 & 7 & 8 & 7 & 7 & 7 & 8 \\
7 & 8 & 6 & 8 & 5 & 6 & 5 & 7 & 7 & 8 & 8 & 6 & 7 & 7 & 8 \\
7 & 8 & 6 & 8 & 5 & 6 & 5 & 8 & 9 & 8 & 8 & 7 & 6 & 6 & 8 \\
7 & 9 & 6 & 7 & 5 & 6 & 6 & 7 & 7 & 7 & 8 & 7 & 8 & 7 & 8 \\
8 & 8 & 6 & 8 & 6 & 6 & 6 & 7 & 9 & 8 & 8 & 6 & 7 & 6 & 8 \\
8 & 7 & 5 & 8 & 6 & 6 & 5 & 7 & 7 & 8 & 9 & 7 & 7 & 7 & 8
\end{array}\right] .
$$

Step 3. The evaluation classes are confirmed. According to the specialists' advice, the evaluation class was divided into four degrees: very good, good, middle, and bad.

Step 4. The four white functions are confirmed. The corresponding grey numbers are identified, and the four white functions are depicted in Figure 1.
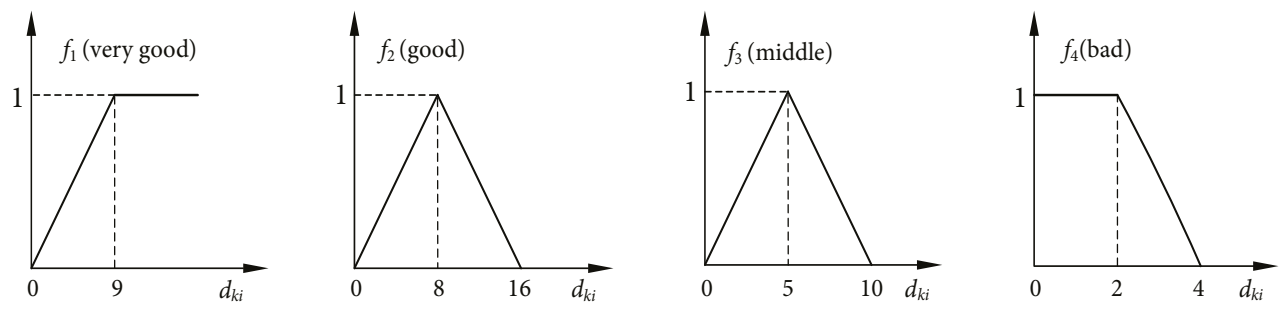

Fig. 1. Four white weight functions

Given a score of " 7 ," the grey numbers that represent the values of $d_{k i}$ in terms of the four evaluation degrees are $\{7 / 9,7 / 8,3 / 5,0\}$.

Steps 5 to 6 . The grey statistics and the fuzzy matrix are calculated. Thus, $n_{i}$ and $r_{i j}(i=$ $1,2, \ldots, 15 ; j=1,2, \ldots, 4)$ can be calculated step by step, and $R$ can be obtained as follows: 


$$
R=\left[\begin{array}{llll}
0.3670 & 0.4128 & 0.2202 & 0 \\
0.4017 & 0.4061 & 0.1922 & 0 \\
0.2871 & 0.3230 & 0.3899 & 0 \\
0.3928 & 0.3960 & 0.2112 & 0 \\
0.2780 & 0.3127 & 0.4093 & 0 \\
0.2917 & 0.3281 & 0.3802 & 0 \\
0.2780 & 0.3127 & 0.4093 & 0 \\
0.3627 & 0.4080 & 0.2294 & 0 \\
0.4373 & 0.3406 & 0.2220 & 0 \\
0.3798 & 0.4273 & 0.1928 & 0 \\
0.4347 & 0.3936 & 0.1717 & 0 \\
0.3276 & 0.3686 & 0.3038 & 0 \\
0.3365 & 0.3785 & 0.2850 & 0 \\
0.3276 & 0.3686 & 0.3038 & 0 \\
0.3841 & 0.4321 & 0.1838 & 0
\end{array}\right] .
$$

Steps 7 to 8. The fuzzy comprehensive matrix and the comprehensive evaluation result are calculated. $B=(0.3404,0.3663,0.2933,0)$ and $Z=B \cdot C=7.4606$. Thus, this ERP system $\left(\mathrm{S}_{1}\right)$ belongs to the "good" class as per a comprehensive suitability evaluation and can be regarded as a candidate ERP system.

\subsubsection{Result obtained with the AWV method}

The simple AWV method is employed extensively for vendor assessment due to its easy implementation (Argyropoulou et al. 2008). The AHP-based approach was also utilized to confirm the weights for multiple criteria evaluation. The comprehensive suitability evaluation result of $S_{1}$ (7.4268) can also be obtained with the weights obtained through the AHP described in Section 4.2 and the average scores of 10 experts.

\subsection{Comparison of the three alternatives and the analysis}

$\mathrm{S}_{2}$ and $\mathrm{S}_{3}$ were comprehensively evaluated in the same manner. The results are listed in Table 11.

Systems $S_{1}$ and $S_{3}$ are the two viable options from among the three alternatives. The results of the AWV method indicated that $S_{3}$ is more suitable than $S_{1}$; thus, $S_{3}$ should be

Table 11. Comparison of comprehensive evaluation for three alternatives

\begin{tabular}{ccccc}
\hline Alternative & Proposed approach & Rank & AWV method & Rank \\
\hline S1 & 7.4606 & 1 & 7.4268 & 2 \\
\hline S2 & 6.1520 & 3 & 1 & 3 \\
\hline S3 & 7.4109 & 2 & 7.5812 & 1 \\
\hline
\end{tabular}


selected if this method is adopted. We checked the available information and determined that $S_{3}$ is cheaper than $S_{1}$; nonetheless, $S_{1}$ has been implemented extensively in similar SMEs. Thus, the selection team believes that $S_{1}$ is better than $S_{3}$ given the low failure rate of the former. Moreover, the overspending for this system is acceptable. Hence, the proposed method can facilitate reliable and reasonable decision making under vague and uncertain condition; in fact, this suggestion made was adopted by company DD.

\section{Conclusions and future research}

Selecting an appropriate ERP system for Chinese SMEs is time consuming because of the complexity of ERP systems, the limited number of dedicated IT staff members, unsubstantial management fundamentals, and the diversity of alternatives. Nonetheless, this task is necessary to facilitate the successful implementation of an ERP project. The main aim of this study is to propose a simple and effective approach for evaluating the candidate SMEoriented ERP systems reasonably. The main contributions of this work are as follows:

1) Considering the special requirement of SMEs in China, reasonable criteria are developed to select the most suitable ERP system for a SME through the group discussion and anonymous questionnaire methods. Therefore, enterprises that are willing to adopt this model must locate qualified experts; some may come from within the market, whereas others may be invited from outside institutions, including universities.

2) A simple and intuitive procedure is established to integrate the objective and subjective data derived from external professional reports and from internal interviews with vendors, respectively. Furthermore, the scoring rules for some factors are presented.

3) An effective and practical approach is adopted to determine the most suitable ERP system for a company under a highly uncertain environment with limited data and information through a systematic and scientific procedure. This integrated algorithm of meta-synthesis incorporates AHP, fuzzy comprehensive evaluation, grey relational analysis; moreover, the reasonable evaluation criteria are determined through modified Delphi. The findings from a case application verify that the proposed model is a persuasive analytical tool for complex multi-criteria decision making under vague and uncertain conditions.

The proposed model is simpler than other mathematical models, such as the fuzzy analytic network process, fuzzy linear regression, and neural network-based approach that incorporates the analytic network process. All the procedures can be handled by the Microsoft Office tool Excel. In addition, this approach can address the limitations of the simple AWV method because the former can reasonably deal with qualitative description information and quantitative data.

The presented approach is a sound investment decision-making tool for ERP systems in SMEs as well as for other information systems. However, this study has certain limitations: (1) the evaluation mechanisms of SME-oriented ERP systems may vary across different industries. Thus, the criteria should be adjusted because we did not consider this situation in this study; (2) although the proposed method generates a satisfactory outcome in ERP system evaluation, we did not have the opportunity to test how the selected ERP system 
helps the enterprise examined in the case study to improve core competence capability. The validity of the proposed model should be studied further through in-depth case studies.

Future research can adopt additional fuzzy multi-attribute approaches, such as the fuzzy technique for order preference by similarity to ideal solution and the fuzzy outranking methods, to estimate the relative weights of effects on ERP system selection. Moreover, an expert system can be integrated into the proposed approach to help managers calculate and interpret the results in each step concisely.

\section{Acknowledgements}

The authors are grateful for the constructive comments of editors and referees. This research is partially supported by National Natural Science Foundation of China (Nos: 71531009; 71371080; 71131004), and Humanities and Social Sciences Foundation of Chinese Ministry of Education (No. 15YJA630095).

\section{References}

Ahmad, M. M.; Cuenca, R. P. 2013. Critical success factors for ERP implementation in SMEs, Robotics and Computer-integrated Manufacturing 29(3): 104-111. http://dx.doi.org/10.1108/17410380610662889

Argyropoulou, M.; Ioannou, G.; Soderquist, K. E.; Motwani, J. 2008. Managing ERP system evaluation and selection in SMEs using the six-imperative methodology, International Journal of Procurement Management 1(4): 430-452. http://dx.doi.org/10.1504/IJPM.2008.018430

Ayağ, Z.; Özdemir, R. G. 2007. An intelligent approach to ERP software selection through fuzzy ANP, International Journal of Production Research 45(10): 2169-2194. http://dx.doi.org/10.1080/00207540600724849

Cebeci, U. 2009. Fuzzy AHP-based decision support system for selecting ERP systems in textile industry by using balanced scorecard, Expert Systems with Application 36(5): 8900-8909. http://dx.doi.org/10.1016/j.eswa.2008.11.046

Czinkota, M. R.; Ronkainen, I. A. 2005. A forecast of globalization, international business and trade: report from a Delphi study, Journal of World Business 40(2): 111-123. http://dx.doi.org/10.1016/j.jwb.2005.02.006

Deep, A.; Guttridge, P.; Dani, S.; Burns, N. 2008. Investigating factors affecting ERP selection in madeto order SME sector, Journal of Manufacturing Technology Management 19: 430-439. http://dx.doi.org/10.1108/17410380810869905

Deng, J. L. 2008. Introduction to grey mathematical resources, Journal of Grey Systems 20(2): 87-92.

Everdingen, Y. Van.; Hillegersberg, J.; Waarts, E. 2000. ERP adoption by European midsize companies, Communication of the Association for Computing Machinery 43: 27-31. http://dx.doi.org/10.1145/332051.332064

Ge, L. P.; Voss, S. 2009. ERP application in China: an overview, International Journal of Production Economics 122(1): 501-507. http://dx.doi.org/10.1016/j.ijpe.2009.06.009

Haddara, M.; Zach, O. 2011. ERP systems in SMEs: a literature review, in Proceedings of the 44th Hawaii International Conference on System Science, 4-7 January 2011, Kauai, Hawaii, 1-10. http://dx.doi.org/10.1109/HICSS.2011.191

Han, Z.; Liu, P. 2011. A fuzzy multi-attribute decision-making method under risk with unknown attribute weights, Technological and Economic Development of Economy 17(2): 246-258.

http://dx.doi.org/10.3846/20294913.2011.580575 
Hicks, D. A.; Stecke, K. E. 1995. The ERP maze: enterprise resource planning and other production and inventory control software, IIE Solutions 27(8): 12-16.

Hsu, C.; Wen, Y. H. 2000. Application of grey theory and multi-objective programming towards airline network design, European Journal of Operational Research 127(1): 44-68.

http://dx.doi.org/10.1016/S0377-2217(99)00320-3

IEEE Standards Board. 1992. IEEE Std. 1061-1992: IEEE standard for a software quality metrics methodology. NY, USA: IEEE Press.

Karaarslan, N.; Gundogar, E. 2009. An application for modular capability-based ERP software selection using AHP method, International Journal of Advanced Manufacturing Technology 42(9-10): 1025-1033. http://dx.doi.org/10.1007/s00170-008-1522-5

Karsak, E. E.; Özogulb, C. O. 2009. An integrated decision making approach for ERP system selection, Expert Systems with Applications 36(1): 660-667. http://dx.doi.org/10.1016/j.eswa.2007.09.016

Kersuliene, V.; Turskis, Z. 2011. Integrated fuzzy multiple criteria decision making model for architect selection, Technological and Economic Development of Economy 17(4): 645-666. http://dx.doi.org/10.3846/20294913.2011.635718

Kumar, A.; Choi, S. K.; Goksel, L. 2011. Tolerance allocation of assemblies using fuzzy comprehensive evaluation and decision support process, International Journal of Advanced Manufacturing Technology 55(1-4): 379-391. http://dx.doi.org/10.1007/s00170-010-3047-y

Laukkanen, S.; Sarpola, S.; Hallikainen, P. 2007. Enterprise size matters: objectives and constraints of ERP adoption, Journal of Enterprise Information Management 20: 319-334.

http://dx.doi.org/10.1108/17410390710740763

Lee, J. W.; Kim, S. H. 2001. An integrated approach for interdependent information system project selection, International Journal of Project Management 19(2): 111-118. http://dx.doi.org/10.1016/S0263-7863(99)00053-8

Liao, X. W.; Li, Y.; Lu, B. 2007. A model for selecting an ERP system based on linguistic information processing, Information Systems 32(7): 1005-1017. http://dx.doi.org/10.1016/j.is.2006.10.005

Marsh, A. 2000. The implementation of enterprise resource planning systems in small-medium manufacturing enterprises in South-East Queensland: a case study approach, in Proceeding of Int. Conference on Management of Innovation and Technology, 12-15 November 2000, Singapore, Singapore, 592-597. http://dx.doi.org/10.1109/ICMIT.2000.916759

National Bureau of Statistics of China. 2011. Industrial classification of national economy (GB/T47542011). Beijing: China Statistics Press.

Newman, M.; Zhao, Y. 2008. The process of enterprise resource planning implementation and business process re-engineering: tales from two Chinese small and medium-sized enterprises, Information Systems Journal 18(4): 405-426. http://dx.doi.org/10.1111/j.1365-2575.2008.00305.x

Onut, S.; Efendigil, T. 2010. A theorical model design for ERP software selection process under the constraints of cost and quality: a fuzzy approach, Journal of Intelligent and Fuzzy Systems 21(6): 365-378. http://dx.doi.org/10.3233/IFS-2010-0457

Poba-Nzaou, P.; Raymond, L. 2012. Managing ERP system risk in SMEs: a multiple case study, Journal of Information Technology 26(3): 170-192. http://dx.doi.org/10.1057/jit.2010.34

Ptak, C. A. 2000. ERP tools, techniques, and applications for integrating the supply chain. St. Lucie Press.

Rao, S. S. 2000. Enterprise resource planning: business needs and technologies, Industrial Management and Data Systems 100: 81-88. http://dx.doi.org/10.1108/02635570010286078

Reuther, D.; Chattopadhyay, G. 2004. Critical factors for enterprise resources planning system selection and implementation projects within small to medium enterprises, in Proceedings of International Engineering Management Conference, 18-21 October 2004, Singapore, Singapore, 851-855.

http://dx.doi.org/10.1109/IEMC.2004.1407502 
Saaty, T. L. 1980. The analytic hierarchy process. New York: McGraw-Hill.

Snider, B.; da Silveira, G. J. C.; Balakrishnan, J. 2009. ERP implementation at SMEs: analysis of five Canadian cases, International Journal of Operations Production and Management 29(1-2): 4-29. http://dx.doi.org/10.1108/01443570910925343

Tambovcevs, A. 2012. ERP system implementation in Latvian manufacturing and construction company, Technological and Economic Development Of Economy 18(1): 67-83. http://dx.doi.org/10.3846/20294913.2012.661176

Tchokogue, A. C.; Bareil, C.; Duguary, C. 2005. Key lessons from the implementation of an ERP at Pratt \& Whitney Canada, International Journal of Production Economics 95(2): 151-163. http://dx.doi.org/10.1016/j.ijpe.2003.11.013

Teltumbde, A. 2000. A framework of evaluating ERP projects, International Journal of Production Research 38(17): 4507-4520. http://dx.doi.org/10.1080/00207540050205262

Umble, E.; Haft, R.; Umble, M. 2003. Enterprise resource planning: implementation procedures and critical success factors, European Journal of Operational Research 146(2): 241-250. http://dx.doi.org/10.1016/S0377-2217(02)00547-7

Wang, L.; Dun, C. X.; Lee, C. G.; Fu, Q. L.; Zeng, Y. R. 2013b. Model and algorithm for fuzzy joint replenishment and delivery scheduling without explicit membership function, International Journal of Advanced Manufacturing Technology 66(9-12): 1907-1920.

http://dx.doi.org/10.1007/s00170-012-4469-5

Wang, L.; Fu, Q. L.; Lee, C. G.; Zeng, Y. R. 2013a. Model and algorithm of fuzzy joint replenishment problem under credibility measure on fuzzy goal, Knowledge-Based Systems 39: 57-66. http://dx.doi.org/10.1016/j.knosys.2012.10.002

Wang, L.; Wang, Z. G.; Liu, S. 2015. An effective multivariate time series classification approach using echo state network and adaptive differential evolution algorithm, Expert Systems with Applications. (in press). http://dx.doi.org/10.1016/j.eswa.2015.08.055

Wang, L.; Zeng, Y. R. 2005. The risk identification and assessment in E-Business development, Lecture Notes in Artificial Intelligence 3614: 1142-1149. http://dx.doi.org/10.1007/11540007_148

Wei, C. C.; Chien, C. F.; Wang, M. J. 2005. An AHP-based approach to ERP system selection, International Journal of Production Economics 96(1): 47-62. http://dx.doi.org/10.1016/j.ijpe.2004.03.004

Wei, C. C.; Wang, M. J. 2004. A comprehensive framework for selecting an ERP system, International Journal of Project Management 22(2): 161-169. http://dx.doi.org/10.1016/S0263-7863(02)00064-9

Xu, Y.; Xie, X. Y.; Zhang, H. G. 2011. Information security testing model based on variable weights fuzzy comprehensive evaluation, China Communications 8(4): 76-83.

Xu, Y. J.; Patnayakuni, R.; Tao, F. F.; Wang, H. M. 2015. Incomplete interval fuzzy preference relations for supplier selection in supply chain management, Technological and Economic Development of Economy 21(3): 379-404. http://dx.doi.org/10.3846/20294913.2013.876688

Yang, J. B.; Wu, C. T.; Tsai, C. H. 2007. Selection of an ERP system for a construction firm in Taiwan: a case study, Automation in Construction 16(6): 787-796. http://dx.doi.org/10.1016/j.autcon.2007.02.001

Yazgan, H. R.; Boran, S.; Goztepe, K. 2009. An ERP software selection process with using artificial neural network based on analytic network process approach, Expert Systems with Applications 36(5): 9214-9222. http://dx.doi.org/10.1016/j.eswa.2008.12.022

Yuen, K. K. F. 2010. Analytic hierarchy prioritization process in the AHP application development: a prioritization operator selection approach, Applied Soft Computing 10(4): 975-989. http://dx.doi.org/10.1016/j.asoc.2009.08.041

Zeng, Y. R.; Wang, L.; He, J. 2012. A novel approach for evaluating control criticality of spare parts using fuzzy comprehensive evaluation and GRA, International Journal of Fuzzy Systems 14(3): 392-401. 
Yu-Rong ZENG. PhD candidate at the School of Management of Huazhong University of Science and Technology. She is also an Associate Professor at the School of Information Engineering of Hubei University of Economics. Author and co-author of more than 20 articles in scientific journals including Expert Systems, Knowledge-based Systems, and International Journal of Fuzzy Systems. Research interests: Decision Making and Information Management.

Lin WANG. PhD, Professor at the School of Management of Huazhong University of Science and Technology. Author and co-author of more than 20 articles in scientific journals including International Journal of Production Economics, Expert Systems with Applications, Knowledge-based Systems, and International Journal of Fuzzy Systems. Research interests: Supply Chain Management, Decision Making, and Optimization Algorithms. He is the corresponding author of this paper.

Xian-Hao XU. PhD, Professor at the School of Management of Huazhong University of Science and Technology. Author and co-author of more than 20 articles in scientific journals including Flexible Services and Manufacturing and International Journal of Production Research. Research interests: Supply Chain Management and Logistics Management. 